\title{
The Opportunities and Limitations of Blended Learning and the Flipped Classroom for Second Language Teaching
}

\author{
Yibu Luo \\ Faculty of Arts, The University of Melbourne, Grattan Street Parkville, Victoria, VIC 3010, Australia \\ 18870817960@163.com
}

\begin{abstract}
Over the last decade, many educators have been investigating the pedagogical effectiveness of blended learning and flipped classroom models. In the conventional teaching process, instructors have been playing an essential role in the lecturing process. Conversely, students lead the learning process in the flipped classroom because they must complete tasks with extracurricular materials and classroom collaboration. Likewise, blended learning also asks students to dominate classroom learning procedures, but its communication medium is a mixture of face-toface and online interaction. This essay evaluates blended learning and the flipped classroom model by evidence of both pros and cons. Lastly, the article concluded that the two new models provide significant reference cases in exploring better practice modes to increase the quality of second language teaching.
\end{abstract}

Keywords: Blended Learning; Flipped Classroom; Motivation in Language Learning; Task-based Teaching.

\section{Introduction}

There is sufficient teaching experience to suggest that traditional education usually occurs in methodological inaccuracies. In the spoon-feeding method, students get frustrated with self-learning and tend to avoid critical thinking. Therefore, many researchers investigate new education modes that can transform learning from passively receiving information to actively inquiring knowledge. Blended and flipped learning are the products of innovation in linguistic pedagogy. However, while more schools promote the two new models, many teachers still lack the skills and relevant knowledge to organize such classroom modes.

Task-based language teaching (TBLT) is commonly used in flipped teaching to activate students' learning motivation. Motivation refers to a psychological condition that triggers and sustains actions to achieve a goal. In Ellis's studies, TBLT highlights "the primary unit for both designing a language programme and for planning individual lessons should be a 'task."” (p. 223) [5]. In other words, TBLT means that students draw on self-study materials to acquire knowledge by themselves [14].

This essay aims to synthesis some studies concerning blended and flipped learning and analyze the two pedagogical approaches' relevance to learning motivation and TBLT. This essay begins with the definitions of blended and flipped learning, introducing their mini distinction. Subsequently, the article evaluates their strengths and limitations by presenting their respective teaching features. Later, we will explore how to associate motivation and TBLT with the two new modes to maximize the effectiveness of language teaching. Lastly, the conclusion summarizes the main views and points out the potential research directions.

\section{What are Blended and Flipped Learning?}

\subsection{The Social Background of Blended Learning}

Now educators in mounting number begin to use blended and flipped learning approaches in English language teaching. Despite its widespread use, it is relatively hard to give an exact definition of the two models because they are still in their infancy [10,12]. Nevertheless, the academic circle has reached some consensus for the two emerging concepts. The historical origin of blended learning may date back to the business community in the 1990s, emerging from professional training courses 
[11]. Along with the rise of and dependence on the internet, more individuals discovered the internet has potential cost-benefit and more flexibility on account of "the reduction in contact time that shifting aspects of delivery online implied." (p. 315) [11]. Consequently, internet use soon spread into interdisciplinary classroom teaching and new pedagogical settings, such as blended learning.

\subsection{The Definition of Blended Learning and the Flipped Classroom}

Currently, many scholars define blended learning as a thoughtful integration of traditional classroom-based teaching, computer-assist learning, and face-to-face interaction [10,11]. Grgurović further stated that the blended learning model is courses where face-to-face and computer-mediated activities are incorporated in syllabus design and practical education [7]. Other advocates mentioned that blended learning provides multiple channels to digital tools for learner-content, peer-peer, and student-teacher interaction [4]. Therefore, blended learning can be regarded as technology-mediated instruction and personalized learning. However, although a blended learning course drives the instructions with computer-assist technology, it is not purely an online class and requires teachers' offline interaction with students.

Flipped classroom teaching, a type of blended learning, refers to giving students course materials at home and practicing it at school [17]. The flipped classroom has two essential features: requiring students to make learning preparation ahead of attending the class; the other is that students play a leading role in classroom instruction with active learning activities [2]. Some subsequent experts like Adnan, Vitta, and Al-Hoorie also stated that flipped teaching turns activities inside the classroom into independent assignments outside the class, increasing student engagement and strengthening their ability to address issues $[1,17]$. Interestingly, the flipped classroom is strongly related to online virtual teaching in blended learning. In a flipped classroom, students must complete readings in advance, respond to pre-class videos questions and collaborate in classroom discussions with the aid of mentors.

\subsection{The Difference between the Two Modes}

While blended learning is often used interchangeably with the flipped classroom, they are not the same concept. Blended learning is the collaboration among offline teaching, web-based instructions, and other syllabus tasks. By comparison, flipped classrooms are that mentors prepare lectures and academic journals that are watched or read at learners' own pace. Mentors assist learners in practicing the new theories acquired in the videos or other relevant materials in the classroom. To put it differently, the flipped classroom does not necessarily have online interaction, whereas online bidirectional communication is an essential component in blended learning. In addition, blended learning does not ask students to preview the lessons before the class. In contrast, flipped classroom implementation is inseparable from autonomous learning outside the class [9]. Significantly, whether in blended learning or flipped classrooms, online teaching does not completely substitute for face-toface interaction but rather is extra support.

\section{Strengths and Limitations}

\subsection{The Advantages of Blended Learning and the Flipped Classroom}

Hockly summarized two drivers of blended learning development: lower costs and high-speed internet [10]. Because of narrow classroom space, students lack sufficient exposure to the target language learning settings for some schools with limited educational facilities. Nonetheless, the online resources can meet the needs of experiencing a language immersion environment. Therefore, online teaching plays a pivotal role in blended learning [11]. Students can draw on computer input systems to learn additional skills like standard pronunciation and advanced composition. Grgurović's interview participant also praised online exercises offer additional training [7]. These exercises also enrich the content of blended learning with TBLT. Some scholars expressed that blended teaching gives students a visual platform beyond geographical constraints to negotiate varying opinions and 
reach an agreement [13]. In such a collaborative project, members may gradually establish interrelation between selected evidence and conclusions based on the absorption of ideas from other teammates. Moreover, Jin's surveys reflected that most participants held positive attitudes towards the blended learning design for argumentative essays [13]. Consequently, an ever-growing number of linguists have started applying blended learning game designs into argumentative writing [13].

Unlike blended learning, flipped classrooms' primary advantage is to enhance students' motivation and decrease their learning anxiety with games [9]. Furthermore, game-based approaches can facilitate social interconnection in class and assist students in facing challenges together [9]. Likewise, one participant in Adnan's studies reported that the flipped classroom makes their learning duration more permanent by continuous communication with teachers and classmates [1]. Such a studentcentered approach ensures that the flipped courses contribute to the student's triumph in obtaining a more flexible and efficient education, particularly on intensive attention.

It is worth noting that the flipped classroom contains "unfocused tasks" in TBLT. Unfocused tasks are designed for practicing the target language in general communication [5]. Less talkative and below-average students are exposed to the natural language use of high proficiency interlocutors. Such unfocused tasks create conditions to practice poor students' output competence, which internalizes and reinforces their understanding of new information [17]. Accordingly, some experts conjectured that the flipped classroom has the most efficacy in conceptual and procedural learning [16]. The reason is that teachers can activate students' high-order mental processes with flipping facilities, such as problem-solving, critical thinking, and strong students' engagement [2].

\subsection{The Disadvantages of the Two Modes}

Despite their enormous benefits, the two modes have many drawbacks that have not been overcome. First, blended learning heavily depends on technical tools and resources, so educators are supposed to update digital tools timely and ensure tools are easy to use. Moreover, this drawback involves access to internet infrastructure. In some economically backward areas, establishing a good network connection is vital to improving educational quality. Second, online resources application also brings new costs like the yearly subscription to databases or good colleges' libraries. This instruction mode may put economic pressure on some underfunded schools.

Similarly, the major problem appears in the flipped classroom. The mandatory application of online resources may exacerbate digital divide dilemmas and the financial burden of low-income families' students. Fortunately, one recent study speculated that current technology development is narrowing the digital divide gap, such as open access to information sharing data resources [15]. Lastly, learners with lower proficiency may not benefit from independent learning before the class [16] because it has strict requirements for students' self-study ability. Therefore, the success of the flipped classroom strongly relies on students' pre-class preparation and self-discipline.

\section{How to Create a Productive Blended Learning or Flipped Classroom Course?}

\subsection{Learning Motivation}

Above all, two disparate types of motivation need to notice: intrinsic and extrinsic motivation. Intrinsic motivation is driven by positive emotions in the struggling process, such as enjoyment and interest [3]. A good case is learners' intellectual satisfaction from fathoming a sophisticated verb conjugation [8]. Extrinsic motivation occurs when individuals put more effort into their work due to external rewards [3]. For instance, students learn a second language for passing the tests and getting relevant professional certificates. Compared to extrinsic motivation, perhaps intrinsic motivation kindles more learning enthusiasm, as learners pursue a sense of gratification and achievement in learning rather than external rewards.

Additionally, one critical factor that can activate students' learning motivation is to meet their interest in course contents and materials, such as situated games [2]. Gamified flipped classroom alleviates students' anxiety about making grammatical mistakes in English dialogue [9]. It enhances 
students' confidence to share varying opinions in English. The intrinsic learning motivation forms in such a sense of achievement subconsciously.

\subsection{The Practice of Flipped Classroom and Blended Learning}

Aside from intrinsic motivation, TBLT is also applicable to the flipped classroom. TBLT aims to facilitate language learning by creating authentic interaction for language practices [6], whereas authenticity is the most important factor for tasks in TBLT [14]. Interestingly, one of the flipped classroom's advantages is to establish an authentic language use environment.

For flipped classrooms, Hung listed four basic principles for designing flipped teaching frameworks. "The $F$ principle of a flexible language learning environment, the $L$ principle of a language learning culture, the $I$ principle of intentional linguistic content, and the $P$ principle of a professional language educator" (p. 188) [12]. Teachers create comprehensible input that matches learners' language ability and individual learning demands in the F principle. The $L$ principle focuses on whether learners dare to exchange their opinions actively in the target language environment. The $I$ principle means building a mechanism with target meaning to relate the pre-class with in-class tasks. In the $P$ principle, teachers are responsible for establishing a transformative language environment in the flipped classroom by their professional skills. The four principles offer substantial theoretical assistance for framing the flipped classroom steps.

For blended learning, Hockly proposed four-step approaches based on the previous research [10]. The first step is to decide the causes for using a blended approach in the current teaching situation and identify negative factors to the curriculum design. The second step determines the dominated educational model, online or face-to-face interaction. Moreover, teachers should design reasonable time plans to identify how much time students will spend on each mode. The third point focuses on the roles of teachers and students in classroom teaching. For example, how to make a transition between offline and technology-based course components, what kinds of communication patterns should be involved, and how much autonomy students will need in group discussion. Lastly, students' classroom performance is a vital analysis criterion. In case students regard autonomous discussion as a big challenge, teachers should arrange some initial learner training next time.

Most notably, both models are not necessarily right for your lesson plans. The choice of both models is up to instructors' teaching objectives. If instructors look to shift the cramming approach into online visual models, blended learning may attract more attention and interest. An overall focus on practicing the theory of information would generally benefit more from the flipped classroom. It is sincerely hoped that these suggestions may support English language educationists in creating more effective blended learning and flipped classroom courses.

\section{Conclusion}

Overall, this article analyzes some studies discussing blended learning and flipped classrooms. These basic findings are consistent with research showing that teachers should adopt both models according to different situations. The introduction opens with the necessity of replacing traditional education methods and gives general statements concerning the definition of motivation and TBLT. In the main body, the first section presents the concept of both models and makes a distinction between them. Besides that, we briefly mentioned the social roots of forming blended learning.

The next section draws on TBLT and language learning motivation to evaluate both modes from economic costs and pedagogical effectiveness. Although blended learning provides students with elearning platforms to receive abundant academic resources, it demands a stable internet connection and relevant database access permissions. The flipped classroom needs both teacher and students' pre-class preparation and close cooperation, so failing is easy if students feel disinclined to preview. For these drawbacks, the priority is to boost learners' intrinsic motivation and help them understand unfamiliar knowledge in a set of situated tasks. Furthermore, educators ought to adjust the specific implementation steps of the two modes depending on students' classroom performance. In sum, while 
the two educational modes might fit learners with independent problem-solving, it needs adequate time to get further perfect in steps. Therefore, experts should conduct future research in more realistic settings to adapt to rapidly changing teaching needs.

\section{References}

[1] Adnan, M. (2017). Perceptions of Senior-year ELT Students for Flipped Classroom: A Materials Development Course. Computer Assisted Language Learning 30 (3-4): 204-222. https:// doi.org/ 10.1080 /09588221.2017.1301958.

[2] Amiryousefi, M. (2017). The incorporation of flipped learning into conventional classes to enhance EFL learners' L2 speaking, L2 listening, and engagement. Innovation In Language Learning and Teaching, 13(2), 147-161. https://doi.org/10.1080/17501229.2017.1394307.

[3] Bower, K. (2019). Explaining motivation in language learning: a framework for evaluation and research. Language Learning Journal, 47(5), 558-574. https://doi.org/10.1080/09571736.2017.1321035.

[4] Crosthwaite, P., Sanhueza, A. G., \& Schweinberger, M. (2021). Training disciplinary genre awareness through blended learning: An exploration into EAP students' perceptions of online annotation of genres across disciplines. Journal of English for Academic Purposes, 53. https:// doi.org/ 10.1016/ j. jeap. 2021. 101021.

[5] Ellis, R. (2009). Task-Based Language Teaching: Sorting Out the Misunderstandings. International Journal of Applied Linguistics, 19(3), 221-246. https://doi.org/10.1111/j.1473-4192.2009.00231.x.

[6] Ellis, R. (2017). Task-based language teaching. In S. Loewen \& M. Sato (Eds.), The Routledge handbook of instructed second language acquisition (pp. 108-125). New York, NY: Routledge.

[7] Grgurović, M. (2013). An application of the Diffusion of Innovations theory to the investigation of blended language learning. Innovation In Language Learning and Teaching, 8(2), 155-170. https:// Doi. org/10.1080/17501229.2013.789031.

[8] Hall, C. J. S., \& P.H. Wicaksono, R. (2011). Additional language education. Mapping Applied Linguistics (pp. 197-220). Routledge.

[9] Ho, J. (2019). Gamifying the flipped classroom: how to motivate Chinese ESL learners? Innovation In Language Learning and Teaching, 14(5), 421-435. https://doi.org/10.1080/17501229.2019.1614185.

[10] Hockly, N. (2018). Blended Learning. ELT Journal: English Language Teaching Journal, 72(1), 97-101. https:// doi.org/10.1093/elt/ccx058.

[11] Hughes, N., Lan Lo, \& Sujing Xu. (2019). Blended Chinese language learning design: an integrative review and synthesis of the literature. Language Learning Journal, 47(3), 313-331. https:// doi.org/ 10. 1080/09571736.2017.1280526.

[12] Hung, H. T. (2017). Design-based research: Redesign of an English language course using a flipped classroom approach. Tesol Quarterly, 51(1), 180-192. https://doi.org/10.1002/tesq.328.

[13] Jin, T., Su, Y., \& Lei, J. (2020). Exploring the blended learning design for argumentative writing. Language Learning \& Technology, 24(2), 23-34. http://hdl.handle.net/10125/44720.

[14] Kessler, M., Solheim, I., \& Zhao, M. (2021). Can Task-based Language Teaching Be "Authentic" in Foreign Language Contexts? Exploring the Case of China. TESOL Journal, 12(1). https:// doi.org/ 10. 1002/ tesj.534.

[15] Sharifi, M., Rostami AbuSaeedi, A., Jafarigohar, M., \& Zandi, B. (2018). Retrospect and prospect of computer assisted English language learning: a meta-analysis of the empirical literature. Computer Assisted Language Learning, 31(4), 413-436. https://doi.org/10.1080/09588221.2017.1412325.

[16] Vitta, J. P., \& Al-Hoorie, A. H. (2020). The flipped classroom in second language learning: A metaanalysis. Language Teaching Research. https://doi.org/10.1177/1362168820981403.

[17] Zarrinabadi, N., \& Ebrahimi, A. (2019). Increasing peer collaborative dialogue using a flipped classroom strategy. Innovation In Language Learning and Teaching, 13(3), 267-276. https:// doi.org/ 10.1080/ 175 01229.2018 .1455688 . 